\title{
Sústalinable Chemistry\& Engineering \\ Extract Nitrogen-Containing Compounds in Biocrude Oil Converted from Wet Biowaste via Hydrothermal Liquefaction
}

Wan-Ting Chen, ${ }^{\dagger}$ Liyin Tang, ${ }^{\dagger \dagger}$ Wanyi Qian, ${ }^{\dagger, \S}$ Karalyn Scheppe, ${ }^{\dagger}$ Ken Nair, ${ }^{\|}$Zhenwei Wu, $^{\dagger}$ Chao Gai, ${ }^{\dagger, \perp}$ Peng Zhang, ${ }^{\dagger}$ and Yuanhui Zhang ${ }^{*}{ }^{\dagger}$

${ }^{\dagger}$ Department of Agricultural and Biological Engineering, University of Illinois at Urbana-Champaign, 1304 West Pennsylvania Avenue, Urbana, Illinois 61801, United States

${ }^{\ddagger}$ College of Environmental \& Resource Sciences, Zhejiang University, 866 Yuhangtang Road, Hangzhou 310058, P. R. China

${ }^{\S}$ Department of Chemical Engineering, Stanford University, 443 Via Ortega, Stanford, California 94305, United States

"Department of Chemical and Biomolecular Engineering, University of Illinois at Urbana-Champaign, 600 South Matthews Avenue, Urbana, Illinois 61801, United States

${ }^{\perp}$ Research Center for Eco-Environmental Sciences, Chinese Academy of Sciences, 18 Shuangqing Road, Beijing 100085, P. R. China

Supporting Information

ABSTRACT: This study demonstrates that water can serve as a green solvent to achieve denitrogenation of biocrude oil converted from wet biowaste via hydrothermal liquefaction (HTL) under previously determined optimal reaction conditions $\left(300{ }^{\circ} \mathrm{C}\right.$ with a $1 \mathrm{~h}$ reaction time for swine manure and Chlorella; $300{ }^{\circ} \mathrm{C}$ with a $0.5 \mathrm{~h}$ reaction time for Spirulina). It was hypothesized that water could extract relatively polar chemicals, such as some of the nitrogen-containing compounds, from HTL biocrude oil. This hypothesis was examined by different extraction techniques using water as a solvent to HTL biocrude oil converted from swine manure

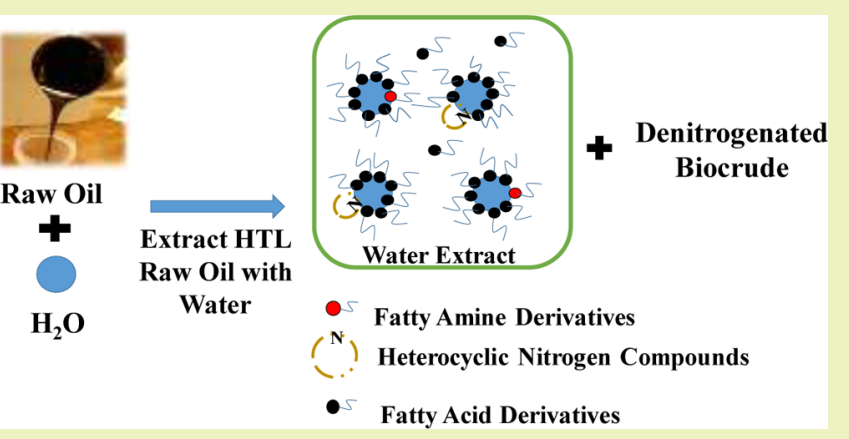
(SM) and low-lipid algae. The water solubilities of biocrude oil and product yields (water extract, biocrude oil, solid residue, and aqueous and gas products) were measured. Compared to that of the biocrude oil without extraction by water, the nitrogen content of biocrude oil converted from SM decreased from 4.32 to $3.23 \%$. Gas chromatography-mass spectrometry (GC-MS) analyses of treated biocrude oil and water extract demonstrated that water can extract nitrogen-containing compounds and separate fatty acid derivatives that were originally in biocrude oil. When an ultrasonically assisted extraction by water was conducted, the nitrogen content in algal biocrude oil decreased from 6.83 to $5.75 \%$ with improved carbon and hydrogen content. In addition, GC-MS analyses of treated biocrude oil and water extract suggest that fatty acid derivatives may behave like surfactants and help in emulsifying nitrogen-containing compounds into water.

KEYWORDS: HTL biocrude oil, Water, Denitrogenation, Wet biowaste, Value-added chemicals

\section{INTRODUCTION}

Wet biowaste, including animal manure and algae harvested from wastewater, is regarded as an attractive biomass feedstock for renewable energy production. Wet biowaste feedstock offers two advantages: (1) for avoiding competition with food crops and land resources and (2) for extraction of energy from a waste source. ${ }^{1,2}$ Furthermore, some aquatic crops, such as algae, can grow faster than terrestrial plants and provide the potential to combine wastewater treatment with aquatic biomass cultivation. ${ }^{2,3}$ Wet biowaste typically contains a large amount of moisture, which requires intensive energy for drying before entering conventional biomass conversion processes such as oilseed extraction techniques. ${ }^{1,4}$ Hydrothermal liquefaction (HTL), involving direct liquefaction of biomass with water, has been demonstrated as an energetically favorable approach to address this issue. ${ }^{4,5}$ Researchers have proven that HTL can convert up to $30-70 \%$ of wet biowaste (dry volatile solids basis) into biocrude oil with heating values between 32 and 38 $\mathrm{MJ} / \mathrm{kg}$, which are $75-90 \%$ of petroleum crude heating values. ${ }^{4,6}$

In general, biocrude oil converted from wet biowaste (e.g., algae) contains a relatively high nitrogen content $(3-7 \%)^{4,9,8}$ for the application of transportation fuels. The high nitrogen content in biocrude oil would cause fouling of conventional oilupgrading catalysts (e.g., zeolites) because the high basicity of the heterocyclic nitrogen ( $\mathrm{N}$-ring) compounds can result in adhesion to acidic active catalytic sites and poison the catalysts. ${ }^{5,9}$ Moreover, the N-ring compounds require significant chemical modifications during the upgrading processes, because they usually need ring hydrogenation to lower the

Received: December 7, 2015

Revised: January 11, 2016

Published: February 15, 2016 


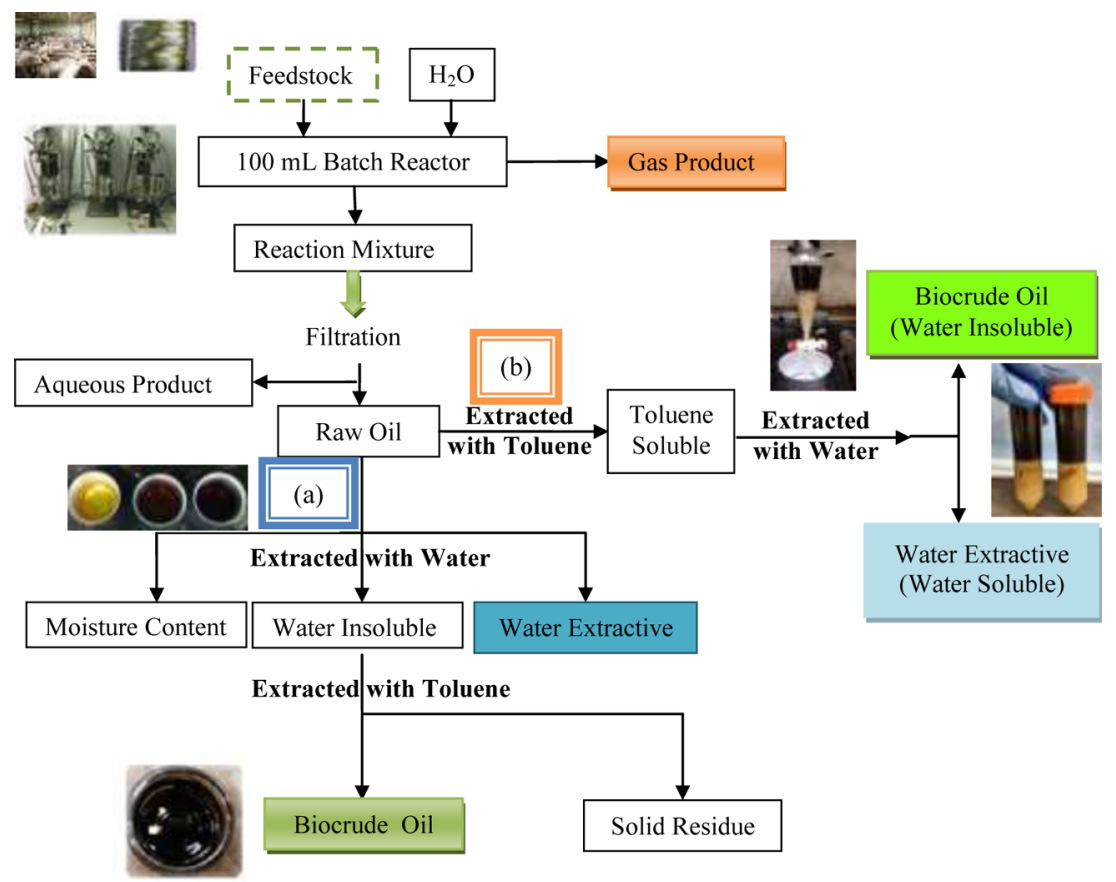

Figure 1. Application of water as a solvent to extract raw oil converted from swine manure and low-lipid algae via HTL. (a) Raw oil was extracted with water and then with toluene, and (b) raw oil was extracted with toluene and then with water.

thermodynamic limitation of the maximal amount of the hydrogenated N-ring compounds. For example, to increase the hydrogenated pyridines to piperidines, the reaction condition has to be shifted to temperatures higher than $387{ }^{\circ} \mathrm{C}$, where hydrogenation of pyridines was yet observed at near atmospheric hydrogen pressure over a $\mathrm{Mo} / \mathrm{Al}_{2} \mathrm{O}_{3}$ catalyst. $^{9-11}$ The $\mathrm{C}-\mathrm{N}$ bond for hydrogenolysis can be significantly weakened by modifying $\mathrm{N}$-ring to $\mathrm{N}$-aliphatic structure so that the denitrogenation can be effectively conducted. ${ }^{5,9-11}$ To overcome these barriers, a suggestion was to optimize the matching of catalysts and hydroprocessing conditions (e.g., identifying the optimal $\mathrm{H}_{2} \mathrm{~S} / \mathrm{H}_{2}$ ratio) to suit a particular feed.' These processes would require multistep chemical modifications, harsh reaction conditions, and complicated catalytic treatments, which inadvertently lead to high capital and operating costs. Thus, alternative approaches to lower the nitrogen content of biocrude oil are critically needed.

Apart from catalytic treatments, adsorption and extraction methods have been extensively investigated for removing nitrogen from petroleum because they are less expensive and can operate under mild conditions (e.g., ambient atmosphere). ${ }^{12,13}$ In addition, it is found that some nitrogencontaining compounds are soluble (e.g., indole) or miscible in water (e.g., pyrazine). ${ }^{7,14}$ On the basis of these findings, it was hypothesized that water can be used as a solvent to extract nitrogen-containing compounds from biocrude oil. Water is a relatively green solvent: it is nontoxic, naturally occurring, nonflammable, and inexpensive. ${ }^{15}$ To examine this hypothesis, three types of biocrude oil, converted from two low-lipid algae and swine manure (SM) via HTL, were extracted with water. Low-lipid algae, Spirulina (SP), and Chlorella (CP), were selected because they can thrive in wastewater effluents ${ }^{1,2,16}$ and their resulting biocrude oil contains a relatively high nitrogen content $(5-7 \%) .{ }^{4,7} \mathrm{SM}$ was chosen as a representative wet biowaste containing a moderate amount of lipid (5-20\%) and a large amount of carbohydrate $(35-44 \%),{ }^{4,7}$ In contrast to low-lipid algae, SM provides a distinct biochemical comparison. To understand how water extraction may affect the mass balance of HTL products and the quality of biocrude oil, water solubility, product yields, elemental compositions, and thermogravimetric analysis (TGA) of biocrude oil and gas chromatography-mass spectrometry (GC-MS) analyses of water extract and biocrude oil were conducted.

\section{MATERIALS AND METHODS}

Feedstock. SM was sampled from the floor of a grower-finisher barn, which was the same type used in previous studies, and the properties were reported. ${ }^{4,7,17,18}$ Before HTL experiments, SM was homogenized using a commercial blender (MX 1000XT, Waring Commercial Inc.). Chlorella pyrenoidosa (CP) were obtained from a health food store as a food grade material (Now Foods). Spirulina algae (SP) were purchased in dry powder form from Cyanotech (Kailua-Kona, HI). The feedstocks used in this study were all stored in a refrigerator at $4{ }^{\circ} \mathrm{C}$ before HTL tests. The total solid content of feedstock was measured as the dry residue at $105{ }^{\circ} \mathrm{C}$ for $24 \mathrm{~h}$. The contents of crude protein, crude fat, and carbohydrate were measured using the Kjeldahl method, Soxhlet extraction, and the phenol/sulfuric acid method, respectively. ${ }^{4,19,20}$ Detailed analyses of SM, SP, and CP are summarized in Table S1 of the Supporting Information.

Hydrothermal Liquefaction (HTL). The HTL experiments were conducted according to the previously reported method, ${ }^{19-22}$ using a stainless steel cylinder batch reactor with a capacity of $100 \mathrm{~mL}$ (model 4593, Parr Instrument Co.). The HTL reaction was conducted under the previously determined optimal conditions for converting microalgae and swine manure into biocrude oil (for SM and $\mathrm{CP}, 300^{\circ} \mathrm{C}$ and $1 \mathrm{~h}$ reaction time; for $\mathrm{SP}, 30{ }^{\circ} \mathrm{C}$ and 0.5 h reaction time) ${ }^{4,6,7,19,23}$ Dry feedstock was mixed with tap water to make the slurry achieve $25 \%$ total solid content by weight for each HTL experiment. The purity of tap water can be found in Table S2. ${ }^{24}$ The reactor was sealed and purged with nitrogen gas three times to remove the residual air in the reactor headspace. Nitrogen gas was again added to the reactor to build a $0.69 \mathrm{MPa}$ gauge initial pressure inside the reactor headspace to prevent water from boiling during the tests. After the HTL reaction at the designated temperature and reaction time, the reactor was cooled to room temperature over $0.5 \mathrm{~h}$ by circulating tap water through the 
cooling coil located outside the reactor. For each type of feedstock, at least two independent HTL experiments were conducted.

Product Separation, Analysis, and Metrics. The HTL products, containing both solid and liquid phases, were first separated by filtration with Whatman glass-fiber filters (Whatman, catalog no. 1822055). The filtration cake was defined as the raw oil. The raw oil was extracted with deionized water in a Soxhlet extractor for $3 \mathrm{~h}$ (modified from ASTM Standard D4072-98 ${ }^{25}$ ) to obtain the water extract (containing water-soluble compounds only). After the extraction with water, the water-insoluble fraction was dried in the oven at $105{ }^{\circ} \mathrm{C}$ for $24 \mathrm{~h}$ and the resulting weight was recorded. Next, the water-insoluble solid fraction was extracted with toluene for $3 \mathrm{~h},{ }^{25}$ and the biocrude oil was obtained at this stage. The fraction that can be extracted by neither water nor toluene was defined as the solid residue. The separation flow is shown in Figure 1 (strategy a).

For ultrasonic-assisted extraction, the raw oil was first extracted with toluene in a Soxhelt extractor for $3 \mathrm{~h} .{ }^{25}$ Afterward, the toluene-soluble fraction (liquid phase) was extracted with deionized water, with the toluene-soluble fraction to water weight ratio being $2: 1,1: 1$, and $1: 2$, in an ultrasonicator (CD-4800, Syhann Co. Ltd.) for 1-30 min with a 60 $\mathrm{Hz}$ frequency. The ultrasonic-assisted extraction by water was conducted with three independent tests. The average value was reported, and the standard deviations are all within $2 \%$. The separation procedure was demonstrated in Figure 1 (strategy b). In short, the HTL raw oil was composed of the water extract, the biocrude oil, and the solid residue, in this study.

According to previously published studies, ${ }^{4,7,19,22}$ the product distribution was calculated on the basis of the dry weight (dw) of feedstock mass by the following equations:

$$
\begin{aligned}
& \text { biocrude oil yield }(\mathrm{dw} \%)=\frac{W_{\text {oil }}}{W_{\text {feed }}} \times 100 \\
& \text { solid residue yield }(\mathrm{dw} \%)=\frac{W_{\text {residue }}}{W_{\text {feed }}} \times 100
\end{aligned}
$$

The yield of the water extract was calculated by two approaches with respect to extraction strategies (a) and (b) (Figure 1). For extraction strategy (a) (Soxhlet extraction), the weight of the raw oil and the water-insoluble fraction were measured with a lab scale while the weight of the moisture was determined by a distillation apparatus. ${ }^{26}$ To estimate if water can extract compounds other than water molecules, water solubility and water content were measured as a fraction of the raw oil. Details are given as eqs 3-5:

$$
\begin{aligned}
& \text { water extract yield }(\mathrm{dw} \%)_{\text {Soxhlet extraction }} \\
& =\frac{W_{\text {raw oil }}-W_{\text {moisture }}-W_{\text {water-insoluble }}}{W_{\text {feed }}} \times 100 \\
& \text { water solubility (\% of raw oil) }=\left(1-\frac{W_{\text {water-insoluble fraction }}}{W_{\text {raw oil }}}\right) \times 100 \\
& \text { water content }\left(\% \text { of raw oil) }=\frac{W_{\text {moisture content }}}{W_{\text {raw oil }}} \times 100\right. \\
& \text { For extraction strategy }(\mathrm{b})(\text { ultrasonic-assisted extraction), the } \\
& \text { weights of the toluene-soluble fraction and the water-insoluble fraction } \\
& \text { were measured with a lab scale: } \\
& \text { water extract yield }(\mathrm{dw} \%) \text { ultrasonic-assisted extraction } \\
& =\frac{W_{\text {toluene-soluble }}-W_{\text {water-insoluble }}}{W_{\text {feed }}} \times 100
\end{aligned}
$$
weights of the toluene-soluble fraction and the water-insoluble fraction

The yield of aqueous and gas products was calculated by difference (Figure 2). Biocrude oil was dried at room temperature in the fume hood for $24 \mathrm{~h}$ prior to the elemental test. Elemental compositions of biocrude oil were determined using a CE 440 elemental analyzer (Exeter Analytical, Inc.). The higher heating value (HHV) of the

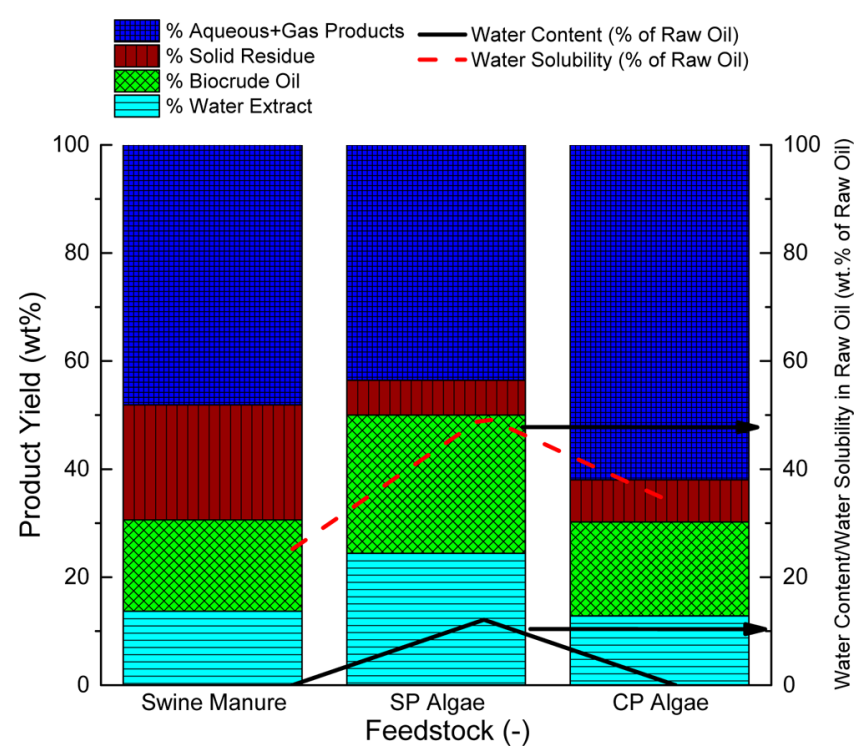

Figure 2. Yields of hydrothermal liquefaction (HTL) products, water content, and water solubility of raw oil converted from different feedstocks. The yield of aqueous and gas products was calculated by difference.

biocrude oil was calculated by using the Dulong formula, based on the elemental composition: $\mathrm{HHV}=0.3383 \mathrm{C}+1.422(\mathrm{H}-\mathrm{O} / 8) .^{21,27}$

The chemical compositions of biocrude oil were analyzed using GC-MS (Agilent Inc., Palo Alto, CA). The internal standard pentadecanoic acid methyl ester $(0.5 \mu \mathrm{M})$ was used for biocrude oil extracted from toluene. Detailed analytical methods were also described previously. ${ }^{28} \mathrm{~A}$ derivatization treatment was applied to the water extract before GC-MS analysis. Dried extracts $(600 \mu \mathrm{L})$ were derivatized with $100 \mu \mathrm{L}$ of methoxyamine hydrochloride $(40 \mathrm{mg} / \mathrm{mL}$ in pyridine) for $1.5 \mathrm{~h}$ at $50{ }^{\circ} \mathrm{C}$ and then with $100 \mu \mathrm{L}$ of MSTFA [ $N$ methyl- $\mathrm{N}$-(trimethylsilyl) trifluoroacetamide] for $2 \mathrm{~h}$ at $50{ }^{\circ} \mathrm{C}$, followed by a $2 \mathrm{~h}$ incubation at room temperature. The internal standard hentriacontanoic acid $(10 \mathrm{mg} / \mathrm{mL})$ was added to each sample prior to derivatization. The derivatized sample was then injected with a split ratio of 7:1. Metabolites were analyzed using a GC-MS system (Agilent Inc., Palo Alto, CA) consisting of an Agilent 7890 gas chromatograph, an Agilent 5975 mass selective detector, and an HP 7683B autosampler. Gas chromatography was performed on a ZB5 MS capillary column (Phenomenex, Torrance, CA). The inlet and MS interface temperatures were $250{ }^{\circ} \mathrm{C}$, and the ion source temperature was adjusted to $230{ }^{\circ} \mathrm{C}$. The helium carrier gas was kept at a constant flow rate of $2 \mathrm{~mL} / \mathrm{min}$. The temperature program was as follows: $5 \mathrm{~min}$ isothermal heating at $70^{\circ} \mathrm{C}$, followed by an oven temperature increase at a rate of $5{ }^{\circ} \mathrm{C} / \mathrm{min}$ to $310^{\circ} \mathrm{C}$ and a final 10 $\min$ at $310{ }^{\circ} \mathrm{C}$. The mass spectrometer was operated in positive electron impact mode (EI) at a $69.9 \mathrm{eV}$ ionization energy over the $\mathrm{m} / z$ $50-800$ scan range. The spectra of all chromatogram peaks were compared with electron impact mass spectrum libraries NIST08 (National Institute of Standards and Technology, Gaithersburg, MD) and W8N08 (Palisade Corp.). To allow comparison between samples, all data were normalized to the internal standard. The instrument variability was within the standard acceptance limit (5\%).

Thermogravimetric analysis (TGA) of biocrude oil was operated with a Q50 TGA instrument (TA Instruments, Schaumburg, IL) from 25 to $800{ }^{\circ} \mathrm{C}$ in $60 \mathrm{~mL} / \mathrm{min} \mathrm{N}_{2}$ at $10{ }^{\circ} \mathrm{C} / \mathrm{min}$ to determine its boiling point distribution.

Biocrude oil obtained by extraction with water and toluene (serial extraction processes) was compared to that with toluene only (single stage). 
Table 1. Elemental Analyses (percentage based on dry weight of samples) of Biocrude Oil Converted from Swine Manure (SM), Chlorella (CP), and Spirulina (SP), with Single-Stage and Serial Extraction Processes (strategy a)

\begin{tabular}{|c|c|c|c|c|c|c|}
\hline element & SM single & SM serial & SP single & SP serial & CP single & $\mathrm{CP}$ serial \\
\hline $\mathrm{C}$ & $76.2 \pm 0.2$ & $76.8 \pm 0.08$ & $74.4 \pm 0.01$ & $74.3 \pm 0.03$ & $75.9 \pm 0.05$ & $74.9 \pm 0.1$ \\
\hline $\mathrm{H}$ & $9.81 \pm 0.05$ & $10.9 \pm 0.2$ & $9.11 \pm 0.00$ & $8.93 \pm 0.1$ & $9.6 \pm 0.01$ & $9.94 \pm 0.05$ \\
\hline $\mathrm{N}$ & $4.32 \pm 0.2$ & $3.23 \pm 0.02$ & $6.83 \pm 0.02$ & $6.74 \pm 0.01$ & $6.07 \pm 0.1$ & $6.18 \pm 0.04$ \\
\hline $\mathrm{O}^{a}$ & 9.71 & 9.11 & 9.71 & 9.75 & 9.71 & 9.03 \\
\hline $\mathrm{H} / \mathrm{C}$ atomic ratio & 1.54 & 1.70 & 1.47 & 1.44 & 1.51 & 1.59 \\
\hline $\mathrm{O} / \mathrm{C}$ atomic ratio & 0.10 & 0.09 & 0.10 & 0.10 & 0.08 & 0.09 \\
\hline $\mathrm{HHV}(\mathrm{MJ} / \mathrm{kg})$ & 38.0 & 39.8 & 36.4 & 36.1 & 37.8 & 37.9 \\
\hline
\end{tabular}

${ }^{a}$ Oxygen content calculated by difference.

\section{RESULTS AND DISCUSSION}

Hydrothermal Liquefaction (HTL) Products Extracted with Water. The yields of water extract, biocrude oil, solid residue, and aqueous along with gas products are summarized in Figure 2. Figure 2 demonstrates that the yield of the water extract is $12.8-24.4 \%$, suggesting that water can be a feasible solvent for HTL raw oil converted from swine manure and lowlipid algae. The yield of the water extract reported in this study is also comparable to the report using relatively polar solvents (e.g., methanol) to extract biocrude oil converted from lignocellulosic biomass. ${ }^{29}$ The water solubility and water content of the raw oil were also reported. Overall, the water solubility (25.2-49.7\%) of the HTL raw oil converted from different feedstocks is higher than the residual water content (0-12.1\%), indicating that water can extract compounds other than water molecules. Relatively polar compounds, such as fatty acids and $\mathrm{N}$-heterocyclic compounds, which were previously distributed in biocrude oil, ${ }^{7,28}$ may be extracted by water. For pyrolysis-derived bio-oil, water has also been used to separate relatively polar compounds (e.g., carboxylic acids) from nonpolar hydrocarbons. ${ }^{30,31}$

Figure 2 also shows that the biocrude oil yield is $16.9-26.8 \%$ when using water as a solvent for HTL raw oil converted from swine manure and low-lipid algae. Chakraborty et al. have explored using water, ethanol, and dichloromethane as solvents in a sequential HTL and multistep extraction process to obtain value-added products, including polysaccharide, bio-oil, and biochar, from Chlorella. ${ }^{32}$ The yields of water extract and bio-oil were reported as 5.6-12 and $20.0-23.4 \%$, respectively. In contrast to another previous study applying tetrahydrofuran, hexane, and ethyl acetate as solvents in a serial extraction procedure to HTL raw oil converted from lignocellulosic feedstock, ${ }^{29}$ the biocrude oil yield reported in this study is similar. The comparison described above implies that water can be an effective and feasible solvent for HTL raw oil converted from swine manure and low-lipid algae.

Elemental Analysis and the Higher Heating Value (HHV) of the Biocrude Oil. Elemental compositions and $\mathrm{HHV}$ of biocrude oil obtained by single-stage and serial extraction processes are listed in Table 1 . The contents of carbon and hydrogen and HHV of biocrude oil extracted with single or serial processes were similar. This suggests that using water as a solvent for HTL raw oil would not affect the energy content of biocrude oil. Furthermore, the hydrogen content and HHV of the biocrude oil converted from SM increased when water was used as the first solvent for HTL raw oil. The fact may be that water can more effectively extract oxygenated chemical compounds from HTL raw oil converted from SM because manure-derived biocrude oil typically contains more oxygenated chemicals, such as carboxylic acids, than algal biocrude oil. ${ }^{7,22}$ Thus, the oxygen content decreased while the hydrogen content increased in the biocrude oil converted from SM. A similar trend was found in biocrude oil converted from Chlorella (CP) when water was used as the first solvent. However, the carbon content was slightly reduced in the treated CP-derived biocrude oil, possibly because of the loss of fatty acids and phenolic derivatives.

On the other hand, Table 1 demonstrates that using water as the first solvent for HTL raw oil can reduce the nitrogen content in biocrude oil converted from SM from 4.32 to $3.23 \%$. The effectiveness of using water to achieve extractive denitrogenation in biocrude oil is noteworthy. Manure-derived biocrude oil generally contains more concentrated fatty acid derivatives. The fatty acid derivatives may serve as a surfactant and help emulsify nitrogen-containing compounds into water. Further GC-MS analyses support this statement. In addition, this denitrogenation efficiency may be partly contributed by the hydrogen bonds (e.g., $\mathrm{O}-\mathrm{H} \cdots \mathrm{N}$ and $\mathrm{O}-\mathrm{H} \cdots \pi)$. The existence of such a bond can be a crucial reason for extracting aromatic nitrogen species from biocrude oil with water. ${ }^{33}$ Similar results have also been reported in the literature using methanol or a methanol/water mixture to extract aromatic organonitrogen compounds from coals. ${ }^{33,34}$

Current denitrogenation of HTL biocrude oil is mostly focused on catalytic treatments at temperatures of 350-450 ${ }^{\circ} \mathrm{C},{ }^{35-37}$ which typically resulted in ineffective nitrogen removal. For example, a $12.3-41.8 \%$ increase in nitrogen content has been observed in our recent catalytic treatment of SM-derived HTL biocrude oil at $350-450{ }^{\circ} \mathrm{C}$ with HZSM-5 as a catalyst. Thereby, using water to reduce the nitrogen content and subsequently applying catalytic treatments to the HTL biocrude oil is recommended. That way, the fouling of conventional oil-upgrading catalysts or adhesion to acidic active catalytic sites, which is caused by the high basicity of the nitrogen-containing compounds, could be reduced.

For algal biocrude oil, extractive denitrogenation with water seems to be ineffective. This may be attributed to the fact that the concentration of fatty acids in the biocrude oil converted from SM is higher than that from low-lipid algae. Biocrude oil converted from SM contains more fatty acid derivatives. For example, the level of $n$-hexadecanoic acid is $2-3$ times greater than that in CP-derived biocrude oil. ${ }^{7,19}$ SM-derived biocrude oil also contains greater varieties of fatty acid derivatives. ${ }^{7,18,38}$ Compared to algal biocrude oil, SM-derived biocrude oil contains not only $n$-hexadecanoic acid but also octadecanoic acid and tetradecanoic acid., ${ }^{4,18}$ Alternative extraction techniques should be considered to improve the extractive 
Table 2. Normalized GC-MS Signals of Components Identified in the Biocrude Oil Converted from Swine Manure (SM), Chlorella (CP), and Spirulina (SP) with Single-Stage (single) and Serial Extraction (serial) Processes

\begin{tabular}{|c|c|c|c|c|c|c|}
\hline \multirow[b]{2}{*}{ compound name } & \multicolumn{6}{|c|}{ normalized signal $(-)$} \\
\hline & SM single & SM serial & SP single & SP serial & $\mathrm{CP}$ single & $\mathrm{CP}$ serial \\
\hline \multicolumn{7}{|l|}{ cyclic oxygenates } \\
\hline deoxyisopodophyllotoxin & 0.35 & 0.04 & $a$ & $a$ & $a$ & $a$ \\
\hline \multicolumn{7}{|l|}{ esters, alcohols, and aldehydes } \\
\hline octadecenal & 1.92 & $a$ & $a$ & $a$ & $a$ & $a$ \\
\hline hexadecanoic acid, methyl ester & 0.04 & $a$ & $a$ & $a$ & 1.13 & $a$ \\
\hline octadecenoic acid, methyl ester & $a$ & $a$ & 0.61 & $a$ & 0.27 & $a$ \\
\hline propyl hexadecanoate & $a$ & $a$ & $a$ & $a$ & 0.58 & $a$ \\
\hline \multicolumn{7}{|l|}{ hydrocarbons } \\
\hline cholest-3-ene, $(5 \alpha)$ - & 0.02 & 0.02 & $a$ & $a$ & $a$ & $a$ \\
\hline$n, n$-octacosadiyne & 0.20 & $a$ & $a$ & $a$ & $a$ & $a$ \\
\hline \multicolumn{7}{|l|}{ phenol derivatives } \\
\hline phenol & 0.23 & $a$ & 0.42 & $a$ & 0.27 & $a$ \\
\hline methyl phenol & 0.008 & $a$ & 0.38 & 0.002 & 0.31 & $a$ \\
\hline \multicolumn{7}{|l|}{ straight amide derivatives } \\
\hline hexadecanamide & 0.82 & $a$ & 0.76 & 0.91 & 1.06 & 1.77 \\
\hline methyl hexadecanamide & 0.02 & $a$ & 1.06 & 2.11 & 0.93 & 1.35 \\
\hline octadecanamide & 0.72 & $a$ & 0.02 & 0.04 & 0.23 & 0.20 \\
\hline octadecenamide & 0.08 & $a$ & $a$ & $a$ & 0.28 & 0.07 \\
\hline methyl octadecanamide & 0.28 & $a$ & $a$ & $a$ & $a$ & $a$ \\
\hline dimethyl octadecanamide & 0.13 & $a$ & $a$ & $a$ & 0.69 & $a$ \\
\hline butyl octadecanamide & 0.01 & $a$ & 0.93 & 1.03 & 0.65 & 1.12 \\
\hline phenylethyl acetamide & 0.08 & $a$ & 0.41 & 0.01 & 0.13 & 0.07 \\
\hline dimethyl dodecanamide & $a$ & $a$ & 0.83 & 1.51 & 0.20 & 1.07 \\
\hline methyl dodecanamide & $a$ & $a$ & $a$ & $a$ & 0.27 & $a$ \\
\hline oleic diethanolamide & $a$ & $a$ & $a$ & $a$ & 0.68 & 0.78 \\
\hline hexadecanamine & $a$ & $a$ & 1.05 & $a$ & $a$ & $a$ \\
\hline \multicolumn{7}{|l|}{$\mathrm{N}$-heterocyclic compounds } \\
\hline indole & 0.04 & $a$ & 0.48 & $a$ & 0.20 & $a$ \\
\hline methylindole & 0.04 & $a$ & 0.36 & $a$ & 0.14 & $a$ \\
\hline dimethyl pyrazine & 0.10 & $a$ & $a$ & $a$ & 0.03 & $a$ \\
\hline hexadecanoic acid, pyrrolidide & 0.04 & $a$ & 0.76 & 0.91 & 0.48 & 0.46 \\
\hline octadecanoic acid, pyrrolidide & 0.13 & $a$ & $a$ & $a$ & 0.06 & $a$ \\
\hline cyclo(leucylprolyl) & $a$ & $a$ & 0.001 & $a$ & 0.10 & 0.04 \\
\hline $9 H$-pyrido $[3,4-b]$ indole & $a$ & $a$ & 0.13 & 0.21 & 0.34 & 0.18 \\
\hline hexanoic acid, morpholide & 0.12 & $a$ & $a$ & $a$ & 0.11 & $a$ \\
\hline octanoic acid, morpholide & $a$ & $a$ & 0.74 & 1.13 & $a$ & $a$ \\
\hline \multicolumn{7}{|l|}{ fatty acids and fatty alcohols } \\
\hline tetradecanoic acid & 0.19 & $a$ & $a$ & $a$ & $a$ & $a$ \\
\hline pentadecanoic acid & 3.21 & $a$ & $a$ & $a$ & $a$ & $a$ \\
\hline hexadecanoic acid & 3.72 & $a$ & 3.44 & 2.34 & 0.50 & 2.26 \\
\hline octadecanoic acid & 6.00 & 0.35 & 0.21 & 0.08 & 0.01 & 0.42 \\
\hline octadecenoic acid & 3.98 & $a$ & 1.61 & 0.17 & 0.03 & 0.75 \\
\hline heptadecanoic acid & 0.28 & $a$ & $a$ & $a$ & $a$ & $a$ \\
\hline octadecadienoic acid & 0.61 & $a$ & $a$ & $a$ & $a$ & $a$ \\
\hline vaccenic acid & 3.89 & $a$ & $a$ & $a$ & $a$ & $a$ \\
\hline eicosanoic acid & 0.19 & $a$ & $a$ & $a$ & $a$ & $a$ \\
\hline butanoic acid & 0.22 & $a$ & $a$ & $a$ & $a$ & $a$ \\
\hline
\end{tabular}

denitrogenation efficiency and reduce the amount of biocrude oil lost into the water extract for algal biocrude oil.

GC-MS Analysis of Biocrude Oil and Water Extract. GC-MS analyses of biocrude oil and water extract were conducted to examine if water can remove nitrogen-containing compounds that were originally distributed in biocrude oil. Major components in biocrude oil and water extract were characterized by GC-MS and are summarized in Tables 2 and 3 , respectively. Identified compounds were categorized into several groups such as straight amide derivatives. GC-MS spectra of biocrude oil and water extract are also available in the Supporting Information. It should be pointed out that only a fraction of the biocrude oil and water extract can be identified by GC-MS. This is due to the fact that the biocrude oil may contain compounds with high molecular weights and boiling points while the water extract may include chemicals that are not volatile. ${ }^{4,17,19}$ Besides, some low-boiling point compounds may be masked by the solvent peak or lost during derivatization 
Table 3. Major Components Identified in the Water Extract Converted from Swine Manure (SM) and Low-Lipid Algae via HTL

\begin{tabular}{|c|c|c|c|}
\hline \multirow[b]{2}{*}{ characterized compound } & \multicolumn{3}{|c|}{ normalized signal $(-)$} \\
\hline & SM & $\begin{array}{l}\text { SP } \\
\text { algae }\end{array}$ & $\begin{array}{l}\mathrm{CP} \\
\text { algae }\end{array}$ \\
\hline \multicolumn{4}{|l|}{ fatty acid derivatives } \\
\hline phosphoric acid & 18.2 & 0.43 & 0.13 \\
\hline hexadecanoic acid & 5.84 & 0.03 & 0.02 \\
\hline octadecanoic acid & 2.00 & 0.03 & 0.02 \\
\hline octadecadienoic acid & 0.19 & 0.007 & 0.004 \\
\hline tetradecanoic acid & 0.25 & $a$ & $a$ \\
\hline dotriacontanol & $a$ & 0.75 & 0.60 \\
\hline glycerol & 0.39 & 0.25 & 0.15 \\
\hline \multicolumn{4}{|l|}{ short chain organic acids $(C<6)$} \\
\hline pyruvic acid & 3.16 & $a$ & $a$ \\
\hline glyoxylic acid & 0.90 & $a$ & $a$ \\
\hline glycolic acid & 0.78 & 0.02 & 0.009 \\
\hline lactic acid & 0.69 & 0.04 & 0.02 \\
\hline succinic acid & 0.60 & 0.02 & 0.006 \\
\hline myoinositol & 0.10 & 0.01 & 0.04 \\
\hline \multicolumn{4}{|l|}{ benzoic acid derivatives } \\
\hline benzoic acid & 0.11 & 0.01 & 0.003 \\
\hline benzenepropanoic acid & 0.67 & 0.02 & 0.003 \\
\hline benzeneacetic acid & 0.46 & 0.002 & $a$ \\
\hline ethoxybenzoic acid & 0.14 & $a$ & $a$ \\
\hline \multicolumn{4}{|l|}{ straight amine derivatives } \\
\hline ethanolamine & 8.56 & 0.006 & 0.003 \\
\hline propylamine & $a$ & 0.02 & 0.02 \\
\hline butylamine & 1.37 & 0.02 & 0.006 \\
\hline butanediamine & $a$ & 0.03 & 0.007 \\
\hline glycine & 0.05 & 0.002 & $a$ \\
\hline$N$-carboxyglycine & 0.73 & 0.02 & 0.07 \\
\hline nitrosophenol & 0.11 & $a$ & $a$ \\
\hline phenylethylamine & $a$ & 0.03 & $a$ \\
\hline phenylethanolamine & $a$ & 0.03 & $a$ \\
\hline methoxytyramine & $a$ & 0.02 & $a$ \\
\hline $\begin{array}{l}\text { 2-amino-5-isopropyl-3,8-dimethyl-1- } \\
\text { azulenecarbonitrile }\end{array}$ & $a$ & 0.02 & $a$ \\
\hline benzocaine & 0.05 & $a$ & $a$ \\
\hline diethanolamine & 0.05 & $a$ & $a$ \\
\hline \multicolumn{4}{|l|}{$\mathrm{N}$-heterocyclic compounds } \\
\hline pyroglutamic acid & 0.84 & 0.31 & 0.02 \\
\hline pyrrolidinone & 0.08 & 0.006 & $a$ \\
\hline aminobenzoxazole & 0.06 & $a$ & $a$ \\
\hline aminoethylcarbazole & $a$ & 0.01 & $a$ \\
\hline methyl acridone & $a$ & 0.02 & $a$ \\
\hline desmethylnoveril & $a$ & 0.01 & $a$ \\
\hline $1 H$-indole-ethanol & $a$ & 0.01 & $a$ \\
\hline indolepropionic acid & $a$ & 0.01 & $a$ \\
\hline diisopropylpiperazindione & 0.05 & $a$ & $a$ \\
\hline \multicolumn{4}{|l|}{ sterol derivatives } \\
\hline cholesterol & 0.15 & $a$ & $a$ \\
\hline
\end{tabular}

of the water extract and evaporation of the toluene used to recover biocrude oil. ${ }^{20}$

Table 2 verifies that extractive denitrogenation with water can help isolate nitrogen-containing compounds from the biocrude oil converted from SM. For example, N-heterocyclic compounds (e.g., octadecanoic acid and pyrrolidide) were not detected in SM-derived biocrude oil when water was used as
Table 4. Boiling Point Distributions of Biocrude Oil Converted from Swine Manure (SM), Chrollera (CP), and Spirulina (SP), and Treated with Single-Stage and Serial Extraction Processes (i.e., with water and toluene) (weight percent)

\begin{tabular}{ccccccc}
$\begin{array}{c}\text { distillate range } \\
\left({ }^{\circ} \mathrm{C}\right)\end{array}$ & $\begin{array}{c}\text { SM } \\
\text { serial }\end{array}$ & $\begin{array}{c}\text { SM } \\
\text { single }\end{array}$ & $\begin{array}{c}\text { SP } \\
\text { serial }\end{array}$ & $\begin{array}{c}\text { SP } \\
\text { single }\end{array}$ & $\begin{array}{c}\text { CP } \\
\text { serial }\end{array}$ & $\begin{array}{c}\text { CP } \\
\text { single }\end{array}$ \\
$25-110$ & 0.15 & 0.91 & 0.60 & 1.13 & 0.62 & 1.08 \\
$110-200$ & 6.85 & 4.05 & 7.83 & 10.6 & 5.80 & 7.95 \\
$200-300$ & 55.8 & 43.9 & 38.5 & 30.4 & 25.7 & 38.2 \\
$300-400$ & 24.6 & 31.0 & 24.4 & 30.6 & 30.7 & 31.3 \\
$400-550$ & 7.92 & 9.74 & 11.9 & 13.6 & 17.3 & 10.8 \\
$550-700$ & 0.55 & 0.54 & 1.48 & 0.84 & 1.42 & 0.60 \\
$700-800$ & 0.70 & 0.15 & 1.31 & 0.42 & 0.60 & 0.66 \\
$>800$ & 3.44 & 9.72 & 14.0 & 12.5 & 17.9 & 9.44 \\
\hline
\end{tabular}

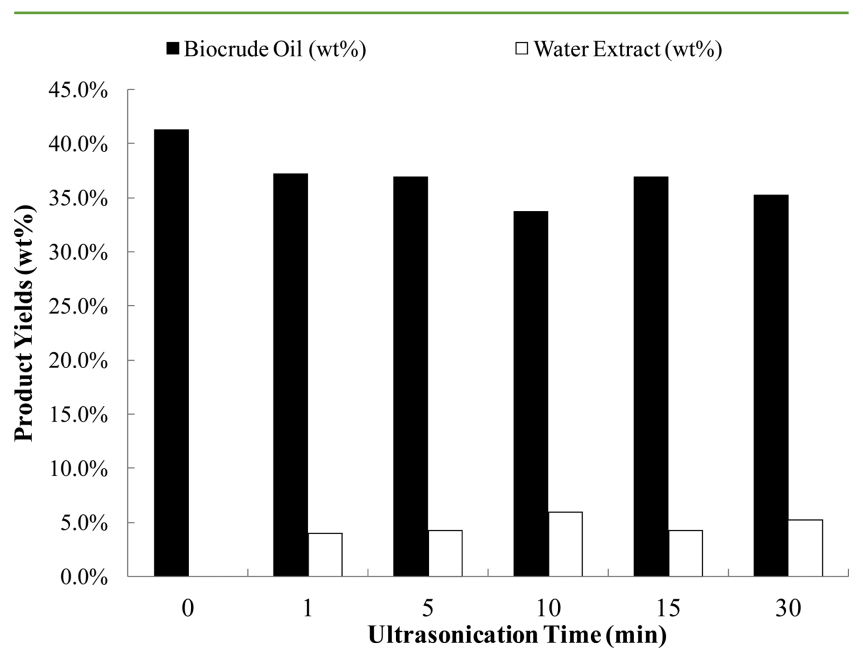

Figure 3. Effect of ultrasonication time (with a 1:1 weight ratio of the toluene-soluble phase to water) on product yields.

the first solvent for HTL raw oil. For algal biocrude oil, the normalized signals of some $\mathrm{N}$-heterocyclic compounds (e.g., indoles) were reduced but not those of straight amide derivatives (e.g., hexadecanamide). This is attributed to the water solubility of $\mathrm{N}$-heterocyclic compounds being higher than that of fatty amide derivatives. ${ }^{14,39}$ For instance, the water solubility of indole is approximately 3 orders of magnitude larger than that of hexadecamide at $25{ }^{\circ} \mathrm{C} .{ }^{40,41}$ Additionally, Table 2 reveals that algal biocrude oil contained more amide derivatives rather than fatty acid derivatives. This finding also supports the hypothesis that the extractive denitrogenation with water works more efficiently for the biocrude oil rich in fatty acid derivatives.

Moreover, Table 2 demonstrates that water can efficiently separate polar value-added chemicals, such as fatty acids, from biocrude oil. For instance, the normalized signal of octadecanoic acid was reduced from 6.00 to 0.35 in SMderived biocrude oil when water was used as the first solvent for HTL raw oil. This fact also suggests that multiple value-added products (e.g., fatty acids and biofuel) can be obtained from the same biomass feedstock with a synergistic design. Applying water as a solvent to extract biocrude oil may help widen the range of application for biocrude oil because the use of fatty acid derivatives is versatile. ${ }^{42}$ For example, fatty acids can serve as a building block for surfactants. ${ }^{43}$

To examine if the water extract contains nitrogen-containing compounds, derivative GC-MS analysis was performed, and 
Table 5. Elemental Compositions of Algal Biocrude Oil Treated with an Ultrasonic-Assisted Extraction with Water for 1-30 min (strategy b)

\begin{tabular}{|c|c|c|c|c|c|c|}
\hline element & $\mathrm{SP}^{a} 1 \mathrm{~min}$ & $\mathrm{SP}, 5 \mathrm{~min}$ & $\mathrm{SP}, 10 \mathrm{~min}$ & $\mathrm{SP}, 15 \mathrm{~min}$ & $\mathrm{SP}, 30 \mathrm{~min}$ & SP, before treatment \\
\hline $\mathrm{C}$ & $74.7 \pm 0.2$ & $75.4 \pm 0.1$ & $75.3 \pm 0.1$ & $75.5 \pm 0.01$ & $73.3 \pm 0.06$ & $74.4 \pm 0.01$ \\
\hline $\mathrm{H}$ & $9.32 \pm 0.1$ & $9.32 \pm 0.1$ & $9.33 \pm 0.1$ & $9.64 \pm 0.1$ & $9.30 \pm 0.2$ & $9.11 \pm 0.00$ \\
\hline $\mathrm{N}$ & $6.58 \pm 0.1$ & $6.51 \pm 0.06$ & $6.44 \pm 0.04$ & $5.89 \pm 0.07$ & $5.75 \pm 0.1$ & $6.83 \pm 0.02$ \\
\hline $\mathrm{O}^{b}$ & 9.42 & 8.82 & 8.89 & 8.97 & 11.7 & 9.66 \\
\hline heating value (MJ/kg) & 36.8 & 37.2 & 37.2 & 37.7 & 35.9 & 36.4 \\
\hline nitrogen removal efficiency (\%) & 3.7 & 4.7 & 5.7 & 13.8 & 15.8 & $\mathrm{~N} / \mathrm{A}$ \\
\hline heating value increment (\%) & 1.2 & 2.1 & 2.1 & 3.4 & -1.3 & $\mathrm{~N} / \mathrm{A}$ \\
\hline
\end{tabular}

the results were summarized in Table 3. Derivative GC-MS analysis demonstrates that water can extract nitrogencontaining compounds (e.g., ethanolamine) and carboxylic acids (e.g., fatty acids) that were originally distributed to biocrude oil. Although the elemental analysis reveals that the extractive denitrogenation with water appeared to be ineffective for algal biocrude oil, Table 3 shows water can extract nitrogencontaining compounds (e.g., N-heterocyclic compounds) from algal biocrude oil. Alternative extraction techniques may improve this extractive denitrogenation efficiency. Table 3 also supports the hypothesis that fatty acid derivatives may behave similarly as surfactants and help emulsify nitrogencontaining compounds into water. For example, phosphoric acid and ethanolamine were found in the water extract. Ethanolamine is widely found in the hydrophobic headgroups of lipid bilayers, ${ }^{44}$ while phosphoric acid is probably produced from the hydrolysis of phosphate esters, ${ }^{4}$ which is one of the major components of the hydrophilic tail in lipid bilayers. ${ }^{45}$ The existence of phosphoric acid and ethanolamine thereby helps elaborate how water extracts nitrogen-containing compounds in this study.

Meanwhile, Table 3 shows that fatty amide derivatives, originally identified in biocrude oil via single-stage extraction, were not found in the water extract. Fatty amide derivatives tend to distribute into the water-insoluble fraction when water is used as the first solvent for HTL raw oil. Besides, the affinity between HTL raw oil and toluene (the second solvent) could change after the raw oil is extracted with water.

Thermogravimetric Analysis (TGA) of Biocrude Oil. To understand how extractive denitrogenation with water may change the boiling point distribution of biocrude oil (Table 4), TGA was performed. Biocrude oil was dried naturally at room temperature in a fume hood for $24 \mathrm{~h}$ and then analyzed via TGA. The distilled fractions between 110 and $550{ }^{\circ} \mathrm{C}$, which can generally enter the petroleum refineries, of the biocrude oil converted from SM and SP were comparable to the literature using a single-stage extraction for the same type of biocrude oil. ${ }^{7,19,20}$ More fractions between 200 and $300{ }^{\circ} \mathrm{C}$ were also obtained in these two kinds of biocrude oil, suggesting that the denitrogenated biocrude oil can be more suitable for further hydrotreatment and enter the refinery for jet fuel and diesel. ${ }^{7}$ On the other hand, the denitrogenated biocrude oil converted from $\mathrm{CP}$ contains more fractions between 400 and $550{ }^{\circ} \mathrm{C}$. This may be attributed to the changing affinity between toluene and the raw oil converted from CP. This denitrogenated biocrude oil may be more suitable for lubrication applications.

Ultrasonic-Assisted Extractive Denitrogenation of Biocrude Oil with Water. Because some nitrogen-containing compounds may be strongly bonded by phenolic species in algal biocrude oil, ${ }^{33}$ the release of nitrogen-containing compounds from algal biocrude oil can be difficult. In addition to the Soxhlet extraction designated by the ASTM methods, ${ }^{25}$ other extraction techniques should be considered. An ultrasonic-assisted extraction was conducted because it has been reported to be an effective extraction method for algal HTL products. $^{27,46}$ Furthermore, to improve the denitrogenation efficiency and reduce the loss of algal biocrude oil in the water extract, a liquid-liquid extraction was conducted with a relatively short period under ultrasonication. Biocrude oil converted from SP was selected for further investigation because it contains the greatest nitrogen content among the three types of biocrude oil tested in this study. Figure 3 shows that the water extract yield was $4-6 \%$ when the ultrasonication was conducted for 1-30 min. Compared to Figure 2, the water extract yield obtained from the ultrasonic-assisted extraction was substantially lower than that obtained from the Soxhlet extraction (13-24\%), indicating the loss of biocrude oil in the water extract was significantly reduced. Additionally, Table 5 shows that the nitrogen content in algal biocrude oil decreased from 6.83 to $5.75 \%$ with an improved heating value of the treated algal biocrude oil. This result indicates that the extractive denitrogenation with water can more efficiently remove the nitrogen content from algal biocrude oil when an ultrasonication is used. Moreover, the carbon and hydrogen contents of the algal biocrude oil increased while the oxygen content decreased as the ultrasonic-assisted extraction with water was conducted. This may be attributed to the fact that the ultrasonic-assisted extraction with water can more effectively extract oxygenated compounds (e.g., phenolic compounds) from algal biocrude oil. ${ }^{31,47}$

The effect of the mixing ratio of the toluene-soluble fraction (liquid phase) and water during the ultrasonic-assisted extraction was also investigated. An ultrasonication time of 15 min was selected because the nitrogen content of algal biocrude oil can be effectively reduced under this condition. Figure S4 demonstrates that changing the ratio of solvents did not significantly change the biocrude oil and water extract yields. However, Table S3 demonstrates that an effective denitrogenation can be realized only with the weight ratio of the toluenesoluble fraction to water being 1:1. The fact may be that the nitrogen-containing compounds were mainly removed by emulsification in this study. To conduct an efficient emulsification, certain amounts of water and the toluenesoluble phase would be needed to create a stable micelle and reach the critical micelle concentration. ${ }^{31,44,47,48}$ 


\section{ASSOCIATED CONTENT}

\section{S Supporting Information}

The Supporting Information is available free of charge on the ACS Publications website at DOI: 10.1021/acssuschemeng.5b01645.

Forage analysis and elemental compositions of three kinds of feedstock used in this study (Table S1), water quality information about Champaign, Urbana, Savoy, Bondville, Saint Joseph, and Pesotum area (Table S2), elemental compositions of algal biocrude oil (Spirulina) treated with an ultrasonic-assisted extraction with different ratios of toluene-soluble phase (Tol) and water (Table S3), thermogravimetric (TG) curves of biocrude oil samples treated with single-stage and serial extraction processes (Figure S1), GC-MS spectra of biocrude oil samples treated with single-stage and serial extraction processes (Figure S2), GC-MS spectra of water extract samples (Figure S3), and the effect of solvent ratio (with a $15 \mathrm{~min}$ ultrasonic-assisted extraction) on product yields (Figure S4) (PDF)

\section{AUTHOR INFORMATION}

\section{Corresponding Author}

*Address: 1304 W. Pennsylvania Ave., Urbana, IL 61801. Phone: +1-217-333-2693. Fax: +1-217-244-0323. E-mail: yzhang1@illinois.edu.

\section{Notes}

The authors declare no competing financial interest.

\section{ACKNOWLEDGMENTS}

The authors appreciate the financial support from the Ministry of Education of Taiwan and the Zhejiang University Education Foundation. The authors also thank the U.S. Department of Agriculture and the Snap Shot Energy Gift Fund for providing experimental supplies for the research. The authors thank Elizabeth Eves and Marie Keel in the Microanalysis Laboratory (Urbana, IL) for their help with elemental analyses. We also greatly appreciate Dr. Alexander Ulanov of the Roy J. Carver Biotechnology Center (Urbana, IL) for his help with and discussion of GC-MS analysis. TGA was conducted in part in the Frederick Seitz Materials Research Laboratory Central Facilities at the University of Illinois.

\section{REFERENCES}

(1) Zhou, Y.; Schideman, L.; Yu, G.; Zhang, Y. A synergistic combination of algal wastewater treatment and hydrothermal biofuel production maximized by nutrient and carbon recycling. Energy Environ. Sci. 2013, 6 (12), 3765-3779.

(2) National Research Council. Sustainable Development of Algal Biofuels in the United States; The National Academies Press: Washington, DC, 2012.

(3) Orfield, N. D.; Fang, A. J.; Valdez, P. J.; Nelson, M. C.; Savage, P. E.; Lin, X. N.; Keoleian, G. A. Life cycle design of an algal biorefinery featuring hydrothermal liquefaction: effect of reaction conditions and an alternative pathway including microbial regrowth. ACS Sustainable Chem. Eng. 2014, 2 (4), 867-874.

(4) Yu, G. Hydrothermal liquefaction of low-lipid microalgae to produce bio-crude oil. Ph.D. Dissertation, University of Illinois at Urbana-Champaign, Urbana, IL, 2012.

(5) Vardon, D. R.; Sharma, B. K.; Blazina, G. V.; Rajagopalan, K.; Strathmann, T. J. Thermochemical conversion of raw and defatted algal biomass via hydrothermal liquefaction and slow pyrolysis. Bioresour. Technol. 2012, 109, 178-187.
(6) He, B. J.; Zhang, Y.; Yin, Y.; Funk, T. L.; Riskowski, G. L. Operating temperature and retention time effects on the thermochemical conversion process of swine manure. Trans. ASAE 2000, 43 (6), 1821-1825.

(7) Chen, W.-T.; Zhang, Y.; Zhang, J.; Schideman, L.; Yu, G.; Zhang, P.; Minarick, M. Co-liquefaction of swine manure and mixed-culture algal biomass from a wastewater treatment system to produce biocrude oil. Appl. Energy 2014, 128, 209-216.

(8) Audo, M.; Paraschiv, M.; Queffélec, C. m.; Louvet, I.; Hémez, J.; Fayon, F.; Lépine, O.; Legrand, J.; Tazerout, M.; Chailleux, E.; Bujoli, B. Subcritical hydrothermal liquefaction of microalgae residues as a green route to alternative road binders. ACS Sustainable Chem. Eng. 2015, 3 (4), 583-590.

(9) Furimsky, E.; Massoth, F. E. Hydrodenitrogenation of petroleum. Catal. Rev.: Sci. Eng. 2005, 47 (3), 297-489.

(10) Yang, S. H.; Satterfield, C. N. Some effects of sulfiding of a NiMoAl2O3 catalyst on its activity for hydrodenitrogenation of quinoline. J. Catal. 1983, 81 (1), 168-178.

(11) Cocchetto, J. F.; Satterfield, C. N. Thermodynamic equilibria of selected heterocyclic nitrogen compounds with their hydrogenated derivatives. Ind. Eng. Chem. Process Des. Dev. 1976, 15 (2), 272-277.

(12) Asumana, C.; Yu, G.; Guan, Y.; Yang, S.; Zhou, S.; Chen, X. Extractive denitrogenation of fuel oils with dicyanamide-based ionic liquids. Green Chem. 2011, 13 (11), 3300-3305.

(13) Zhang, H.; Li, G.; Jia, Y.; Liu, H. Adsorptive removal of nitrogen-containing compounds from fuel. J. Chem. Eng. Data 2010, 55 (1), 173-177.

(14) Baysinger, G. CRC Handbook of Chemistry and Physics; CRC Press: Boca Raton, FL, 2014.

(15) Lancaster, M. Green chemistry: An introductory text; Royal Society of Chemistry: London, 2010.

(16) Kosaric, N.; Nguyen, H.; Bergougnou, M. Growth of Spirulina maxima algae in effluents from secondary waste-water treatment plants. Biotechnol. Bioeng. 1974, 16 (7), 881-896.

(17) Vardon, D. R.; Sharma, B. K.; Scott, J.; Yu, G.; Wang, Z.; Schideman, L.; Zhang, Y.; Strathmann, T. J. Chemical properties of biocrude oil from the hydrothermal liquefaction of Spirulina algae, swine manure, and digested anaerobic sludge. Bioresour. Technol. 2011, 102 (17), 8295-8303.

(18) Wang, Z. Reaction mechanisms of hydrothermal liquefaction of model compounds and biowaste feedstocks. Ph.D. Dissertation, University of Illinois at Urbana-Champaign, Urbana, IL, 2011.

(19) Gai, C.; Zhang, Y.; Chen, W.-T.; Zhang, P.; Dong, Y. Energy and nutrient recovery efficiencies in biocrude oil produced via hydrothermal liquefaction of Chlorella pyrenoidosa. RSC Adv. 2014, 4 (33), 16958-16967.

(20) Gai, C.; Zhang, Y.; Chen, W.-T.; Zhang, P.; Dong, Y. An investigation of reaction pathways of hydrothermal liquefaction using Chlorella pyrenoidosa and Spirulina platensis. Energy Convers. Manage. 2015, 96, 330-339.

(21) Yu, G.; Zhang, Y. H.; Schideman, L.; Funk, T.; Wang, Z. C. Distributions of carbon and nitrogen in the products from hydrothermal liquefaction of low-lipid microalgae. Energy Environ. Sci. 2011, 4 (11), 4587-4595.

(22) Chen, W.-T.; Ma, J.; Zhang, Y.; Gai, C.; Qian, W. Physical pretreatments of wastewater algae to reduce ash content and improve thermal decomposition characteristics. Bioresour. Technol. 2014, 169, 816-820.

(23) Pham, M.; Schideman, L.; Sharma, B. K.; Zhang, Y.; Chen, W.$\mathrm{T}$. Effects of hydrothermal liquefaction on the fate of bioactive contaminants in manure and algal feedstocks. Bioresour. Technol. 2013, $149,126-135$.

(24) Illinois American Water. Annual water quality report (Champaign District). http://www.amwater.com/ilaw/customerservice/water-quality-reports.html (accessed November 19, 2015).

(25) ASTM D4072-98: Standard test method for toluene-insoluble (TI) content of tar and pitch. In Annual Book of ASTM Standards; ASTM International: West Conshohocken, PA, 2004. 
(26) ASTM D95-99: Standard test method for water in petroleum products and bituminous materials by distillation. In Annual Book of ASTM Standards; ASTM International: West Conshohocken, PA, 2004.

(27) Zhang, J.; Chen, W.-T.; Zhang, P.; Luo, Z.; Zhang, Y. Hydrothermal liquefaction of Chlorella pyrenoidosa in sub- and supercritical ethanol with heterogeneous catalysts. Bioresour. Technol. 2013, 133, 389-397.

(28) Chen, W.-T.; Zhang, Y.; Zhang, J.; Yu, G.; Schideman, L. C.; Zhang, P.; Minarick, M. Hydrothermal liquefaction of mixed-culture algal biomass from wastewater treatment system into bio-crude oil. Bioresour. Technol. 2014, 152, 130-139.

(29) Yang, X.; Lyu, H.; Chen, K.; Zhu, X.; Zhang, S.; Chen, J. Selective extraction of bio-oil from hydrothermal liquefaction of Salix psammophila by organic solvents with different polarities through multistep extraction separation. BioResources 2014, 9 (3), 5219-5233.

(30) Vitasari, C. R.; Meindersma, G. W.; de Haan, A. B. Water extraction of pyrolysis oil: The first step for the recovery of renewable chemicals. Bioresour. Technol. 2011, 102 (14), 7204-7210.

(31) Li, Y.; Wang, T.; Liang, W.; Wu, C.; Ma, L.; Zhang, Q.; Zhang, $\mathrm{X}$.; Jiang, T. Ultrasonic preparation of emulsions derived from aqueous bio-oil fraction and $0 \#$ diesel and combustion characteristics in diesel generator. Energy Fuels 2010, 24 (3), 1987-1995.

(32) Chakraborty, M.; Miao, C.; McDonald, A.; Chen, S. Concomitant extraction of bio-oil and value added polysaccharides from Chlorella sorokiniana using a unique sequential hydrothermal extraction technology. Fuel 2012, 95, 63-70.

(33) Wei, X.-Y.; Wang, X.-H.; Zong, Z.-M. Extraction of organonitrogen compounds from five Chinese coals with methanol. Energy Fuels 2009, 23 (10), 4848-4851.

(34) Kodera, Y.; Ukegawa, K.; Mito, Y.; Komoto, M.; Ishikawa, E.; Nakayama, T. Solvent extraction of nitrogen compounds from coal liquids. Fuel 1991, 70 (6), 765-769.

(35) Cheng, D.; Wang, L.; Shahbazi, A.; Xiu, S.; Zhang, B. Catalytic cracking of crude bio-oil from glycerol-assisted liquefaction of swine manure. Energy Convers. Manage. 2014, 87, 378-384.

(36) Duan, P.; Savage, P. E. Catalytic treatment of crude algal bio-oil in supercritical water: optimization studies. Energy Environ. Sci. 2011, 4 (4), 1447-1456.

(37) Zhang, C.; Duan, P.; Xu, Y.; Wang, B.; Wang, F.; Zhang, L. Catalytic upgrading of duckweed biocrude in subcritical water. Bioresour. Technol. 2014, 166, 37-44.

(38) Xiu, S.; Shahbazi, A.; Shirley, V. B.; Wang, L. Swine manure/ crude glycerol co-liquefaction: physical properties and chemical analysis of bio-oil product. Bioresour. Technol. 2011, 102 (2), 19281932.

(39) Richmond, J. Cationic Surfactants: Organic Chemistry; CRC Press: Boca Raton, FL, 1990.

(40) Yalkowsky, S. H.; He, Y.; Jain, P. Handbook of aqueous solubility data; CRC Press: Boca Raton, FL, 2010.

(41) Wishart, D. S.; Jewison, T.; Guo, A. C.; Wilson, M.; Knox, C.; Liu, Y.; Djoumbou, Y.; Mandal, R.; Aziat, F.; Dong, E.; Bouatra, S.; Sinelnikov, I.; Arndt, D.; Xia, J.; Liu, P.; Yallou, F.; Bjorndahl, T.; Perez-Pineiro, R.; Eisner, R.; Allen, F.; Neveu, V.; Greiner, R.; Scalbert, A. Nucleic Acids Res. 2013, 41 (D1), D801-D807.

(42) Handke, P.; Lynch, S. A.; Gill, R. T. Application and engineering of fatty acid biosynthesis in Escherichia coli for advanced fuels and chemicals. Metab. Eng. 2011, 13 (1), 28-37.

(43) Maag, H. Fatty acid derivatives: important surfactants for household, cosmetic and industrial purposes. J. Am. Oil Chem. Soc. 1984, 61 (2), 259-267.

(44) Lai, M.-H.; Lee, S.; Smith, C. E.; Kim, K.; Kong, H. Tailoring polymersome bilayer permeability improves enhanced permeability and retention effect for bioimaging. ACS Appl. Mater. Interfaces 2014, 6 (13), 10821-10829.

(45) Seelig, J.; MacDonald, P. M.; Scherer, P. G. Phospholipid head groups as sensors of electric charge in membranes. Biochemistry 1987, 26 (24), 7535-7541.
(46) Li, H.; Liu, Z.; Zhang, Y.; Li, B.; Lu, H.; Duan, N.; Liu, M.; Zhu, $\mathrm{Z}$.; Si, B. Conversion efficiency and oil quality of low-lipid high-protein and high-lipid low-protein microalgae via hydrothermal liquefaction. Bioresour. Technol. 2014, 154, 322-329.

(47) Luo, J.; Fang, Z.; Smith, R. L., Jr Ultrasound-enhanced conversion of biomass to biofuels. Prog. Energy Combust. Sci. 2014, 41, 56-93.

(48) Lai, M.-H.; Clay, N. E.; Kim, D. H.; Kong, H. Bacteriamimicking nanoparticle surface functionalization with targeting motifs. Nanoscale 2015, 7 (15), 6737-6744. 